\title{
Preparing nurses for global health care
}

\author{
Lynda Law Wilson
}

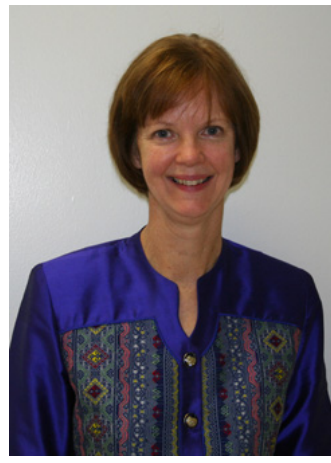

In 2009, the World Health Organization published a document proposing global standards for the initial education of professional nurses and midwives, and noted that although nearly 35 million nurses and midwives make up the largest cadre of health care workers globally, they are rarely involved in high level decision-making and policy development ${ }^{(1)}$. The development of the standards addressed one of the goals of the WHA59.23 resolution adopted in $2006^{(2)}$, to develop global nursing education standards as a strategy for strengthening nursing and midwifery in order to achieve the Millennium Development Goals (MDGs) for health ${ }^{(1,3)}$. The standards specify that graduates of initial nursing and midwifery educational programs should be culturally competent, have an understanding of the social determinants of health, and have the ability to practice and meet population health needs in the health care systems of their respective countries ${ }^{(1)}$. The standards do not explicitly address the need to prepare nurses who have competencies in global health.

In this era of increased geographic mobility, the emergence of emerging infections that cross national borders, technological and communication advances, and the growing interdependence of the world, there is a need to move beyond a focus on local and national health care problems to ensure that all nurses are prepared to address local, national, and global health needs ${ }^{(4-7)}$.

Global health has been defined as "...an area for study, research, and practice that places a priority on improving health and achieving equity in health for all people worldwide. Global health emphasizes transnational health issues, determinants, and solutions; involves many disciplines within and beyond the health sciences and promotes interdisciplinary collaboration; and is a synthesis of population based prevention with individual-level clinical care ${ }^{\prime \prime(8)}$. Although there have been numerous efforts to define cultural competencies to be integrated into nursing curricula(9-11), efforts to identify and define global health competencies are just beginning. It is important for nursing educators to develop innovative curricula to prepare nurses for roles in a global society ${ }^{(12)}$. Specific global health concepts to be integrated into basic nursing educational programs include: global citizenship, social justice, health equity, global health nursing issues, determinants of health, epidemics, communicable and non-communicable diseases, epidemiology and health outcomes, and humanitarian emergencies ${ }^{(13)}$. Faculty from the Pan American Health Organization (PAHO)/World Health Organization (WHO) Nursing and Midwifery Collaborating Centers at the University of Alabama at Birmingham, the University of Sao Paulo at Ribeirao Preto, the National University of Mexico, and Johns Hopkins University have recently collaborated on a project to survey nursing faculty in North America and Latin America to identify their perceptions of global health competencies that should be included in basic nursing curricula(14) The survey instrument was developed by adapting a set of global health competencies for medical students that had been developed by the Association of Faculties of 
Medicine of Canada (AFMC) Resource Group on Global Health and the Global Health Education Consortium (GHEC) http://globalhealthcompetencies.wikispaces.com/. Invitations to complete the anonymous online surveys were sent via email to nursing faculty members in Canada, Caribbean Countries, Latin America, and the United States. Surveys were available in English, Spanish, and Portuguese. To date, 542, 51, and 224 responses have been received to the English, Spanish, and Portuguese surveys, respectively. It is recognized that there is a need for further work to develop consensus among the global nursing community about which, if any, global health competencies are essential for different levels of professional nursing educational programs. In view of the rapid developments in globalization of health care, I suggest that now is the time for nurses and midwives to be prepared as competent global health citizens and practitioners.

\section{References}

1. World Health Organization. Global standards for the initial education of professional nurses and midwives. Geneva (SWZ): WHO; 2009.

2. World Health Organization. Scaling up health workforce production: a concept paper towards the implementation of World Health Assembly resolution WHA59.23 Geneva: World Health Organization; 2006.

3. United Nation. We can end poverty 2015: Millennium Development Goals [Internet]. [cited 2010 Ago 26]. Available from: http://www.un.org/millenniumgoals/

4. Baumann A, Blythe J. Globalization of higher education in nursing. Online J Issues Nurs. [Internet]. 2008;13(2):113. [cited 2010 Ago 26]. Available from: http://www.medscape.com/viewarticle/576193

5. Bradbury-Jones C. Globalisation and its implications for health care and nursing practice. Nurs Standard. $2009 ; 23(25): 43-7$.

6. Callen BL, Lee JL. Ready for the world: Preparing nursing students for tomorrow. J Prof Nurs. 2009;25(5):292-8.

7. Ogilvie LD, Paul P. Burgess-Pinto E. International dimensions of higher education in nursing in Canada: Tapping the wisdom of the 20th century while embracing the possibilities for the 21st century. Int J Nurs Educ Scholar. 2007;4(1):1-22.

8. Koplan JP, Bond TC, Merson MH, Reddy KS, Rodriguez MH, Sewankambo NK, Wasserheit JN. Towards a common definition of global health. Lancet. 2009;373(9679):1993-5.

9. American Association of Colleges of Nursing. Essentials of baccalaureate education for professional nursing practice. Washington: American Association of Colleges of Nursing; 2008.

10. Douglas MK, Pierce JU, Rosenkoetter M, Callister LC, Hattar-Pollara M, Lauderdale J, Pacquiao D. Standards of practice for culturally competent nursing care: A request for comments. J Transcult Nurs. 2009;20(3):257-69.

11. International Council of Nurses. Cultural and linguistic competence. Position statement. [Internet]. [cited 2010 Ago 20]. Available from: http://www.icn.ch/images/stories/documents/publications/position_statements/B03_ Cultural_Linguistic_Competence.pdf

12. Mill J, Astle BJ, Ogilvie L, Gastardo DG. Linking global citizenship, undergraduate nursing education, and professional nursing: Curricular innovation in the 21st century. ANS Adv Nurs Sci. 2010;33(3):E1-E11.

13. Archambault N. Incorporating global health into undergraduate nursing education. MSN, Vancouver: University of British Columbia; 2010.

14. Wilson L, Harper DC, Tami I, Zarate R, Salas S, Farley J, Ventura C. Global Health Competencies for Nurses in the Americas. J Prof Nurs. 2011. (In Press).

Lynda Law Wilson is RN, PhD, FAAN, Professor and Assistant Dean for International Affairs and Deputy Director, PAHO/ WHO Collaborating Center for International Nursing. School of Nursing, University of Alabama at Birmingham, USA. Associate Editor, Revista Latino-Americana de Enfermagem. E-mail: Iyndawilson@uab.edu. 